\title{
Maia type fixed point results via C-class function
}

\author{
Arslan Hojat Ansari \\ Department of Mathematics, \\ Karaj Branch, Islamic Azad University, \\ Karaj, Iran \\ email: mathanalsisamir4@gmail.com
}

\author{
Mohammad Saeed Khan \\ Department of Mathematics \& \\ Statistics, Sultan Qaboos University, \\ P. O. Box 36, Al-Khoud 123,Muscat, \\ Sultanate of Oman \\ email: mohammad@squ.edu.om
}

\author{
Vladimir Rakočević \\ Faculty of Sciences and Mathematics, \\ Višegradska 33, 18000 Niš, Serbia \\ email: vrakoc@sbb.rs (corresponding author)
}

\begin{abstract}
In 1968, M. G. Maia [16] generalized Banach's fixed point theorem for a set $X$ endowed with two metrics. In 2014, Ansari [2] introduced the concept of $\mathrm{C}$-class functions and generalized many fixed point theorems in the literature. In this paper, we prove some Maia's type fixed point results via C-class function in the setting of two metrics space endowed with a binary relation. Our results, generalized and extended many existing fixed point theorems, for generalized contractive and quasi-contractive mappings, in a metric space endowed with binary relation.
\end{abstract}

\section{Introduction and preliminaries}

The classical Banach contraction mapping is one of the most useful in metric fixed point theory. It is very popular tool for solving existence and uniqueness

2010 Mathematics Subject Classification: 46N40, 47H10, 54H25, 46T99

Key words and phrases: fixed point, generalized contraction mappings, ordered metric spaces, C-class function 
problems in many different fields of mathematics. Due to its importance and applications potential, the Banach Contraction Principle has been investigated heavily by many authors. Consequently, a number of generalizations of this celebrated principle have appeared in the literature. For some recent significant book from fixed point theory, we refer to $([1,7,11,14,17,24,26])$.

We first recall Maia's fixed point theorem:

Theorem 1 [16] Let $(\mathrm{X}, \mathrm{d}, \delta)$ be a bimetric space and $\mathrm{T}: \mathrm{X} \rightarrow \mathrm{X}$. Assume that the following conditions are satisfied:

(i) $\mathrm{d}(\mathrm{x}, \mathrm{y}) \leq \delta(x, y)$ for all $x, y \in X$,

(ii) $\mathrm{X}$ is complete with respect to $\mathrm{d}$,

(iii) $\mathrm{T}$ is continuous with respect to $\mathrm{d}$,

(iv) there exists a constant $\alpha \in[0,1)$ such that

$$
\delta(\mathrm{T} x, \mathrm{Ty}) \leq \alpha \delta(x, y), \quad \text { for all } \quad x, y \in X .
$$

Then $\mathrm{T}$ has a unique fixed point in $\mathrm{X}$.

Singh [28] proved that the above theorem is true under much less restricted condition, that is we do not need the continuity of $T$ with respect to $d$ on $X$, but only the continuity at a point. Many papers deal with fixed point theorems of Maia type and with applications (see eg., [6, 5, 19, 23, 22, 25, 20, 30]) and references therein). In these direction, in 2019. Petrusel and Rus [20] consider the following: Let $X$ be nonempty set endowed with a metric $d$, an order relation $\preceq$ and an operator $f: X \rightarrow X$, which satisfies two main assumptions:

(1) $f$ is generalized monotone with respect to $\preceq$;

$(2) f$ is a (generalized) contraction with respect to $d$ on a certain subset $Y$ of $X \times X$.

Then, they apply these results to study some problems related to integral and differential equations, and several open questions are discussed. We point out that Turinici [30] have showed that the Ran-Reurings [21] fixed point theorem is but a particular case of Maia's.

In 2012. Samet and Turinici [27] introduced the notion of contractive mapping in a metric space endowed with amorphous binary relation. They showed a theorem subsumes many known results in the literature. For further study about contractive mappings in a metric space endowed with binary relation, we refer the reader to [8] [27] and [31]. 
In the sequel let $(X, d, \delta)$ be a bimetric space and $T: X \rightarrow X$ be a mapping. Denote by

$$
\operatorname{Fix}(T)=\left\{x^{*} \in X: x^{*}=T x^{*}\right\} .
$$

the set of all fixed points of $\mathrm{T}$ in $\mathrm{X}$.

Let $\mathcal{R}$ be a binary relation on $\mathrm{X}$ and let $\mathcal{S}$ be the symmetric binary relation defined by

$$
x, y \in X, \quad x \mathcal{S} y \quad \Longleftrightarrow \quad x \mathcal{R} y \text { or } y \mathcal{R} x .
$$

For $x_{0} \in X$ we define the sequence $\left\{x_{n}\right\}$ by

$$
x_{n}=T x_{n-1} \quad \text { for all } n \in \mathbb{N} \text {. }
$$

Definition 1 Let $(X, \delta)$ be metric space and $\mathrm{n} \in \mathbb{N} \cup\{0\}$. For $\mathrm{A} \subset \mathrm{X}$ we denote by $\operatorname{diam}(A):=\sup \{\delta(a, b): a, b \in A\}$ the diameter of $A$. For each $x_{0} \in X$ the orbit sets of $\mathrm{T}$ at $\mathrm{x}_{0}$ are defined as following

$$
\mathrm{O}_{n}\left(x_{0}\right)=\left\{x_{0}, x_{1}, \ldots, x_{n}\right\} \quad \text { and } \quad O_{\infty}\left(x_{0}\right)=\left\{x_{0}, x_{1},, x_{2}, \ldots\right\} .
$$

We say that $(\mathrm{X}, \delta)$ is $\mathrm{T}$-orbitally complete iff every $\delta$-Cauchy sequence from $\mathrm{O}_{\infty}(\mathrm{x})$ for some $\mathrm{x} \in \mathrm{X}$ converges in $\mathrm{X}$.

Definition 2 [27] A subset $\mathrm{D}$ of $\mathrm{X}$ is called $\mathcal{R}$-directed if for every $\mathrm{x}, \mathrm{y} \in \mathrm{D}$, there exists $z \in \mathrm{X}$ such that $z \mathcal{R} x$ and $z \mathcal{R} y$.

Definition 3 A mapping $\mathrm{T}: \mathrm{X} \rightarrow \mathrm{X}$ is called $\mathcal{R}$-preserving mapping if

$$
x, y \in X, \quad x \mathcal{R} y \quad \Longrightarrow \quad \mathrm{T} x \mathcal{R} \mathrm{Ty} .
$$

Next, we define the set $\Phi$ of functions $\varphi:[0,+\infty) \rightarrow[0,+\infty)$ satisfying:

(I) $\varphi$ is nondecreasing,

(II) $\sum_{n=1}^{\infty} \varphi^{n}(t)<\infty$ for each $t>0$, where $\varphi^{n}$ is the $n$-th iterate of $\varphi$.

Remark 1 Let $\varphi \in \Phi$. We have $\varphi(\mathrm{t})<\mathrm{t}$ for all $\mathrm{t}>0$.

Remark 2 Let $\varphi \in \Phi$. We have $\lim _{\mathfrak{n} \rightarrow \infty} \varphi^{\mathfrak{n}}(\mathrm{t})=0$ for all $\mathrm{t}>0$. 
Definition 4 [15] Assume that for $\mathrm{T}: \mathrm{X} \rightarrow \mathrm{X}$ there exists $\varphi \in \Phi$ such that

$$
\delta(\mathrm{T} x, \mathrm{Ty}) \leq \varphi\left(\mathrm{M}_{\delta}(\mathrm{x}, \mathrm{y})\right) \quad \text { for all } \mathrm{x}, \mathrm{y} \in \mathrm{X} \quad \text { with } \quad \mathrm{xSy} .
$$

A mapping $\mathrm{T}$ is called a generalized contractive with respect to $\delta$ if

$$
M_{\delta}(x, y)=\max \left\{\delta(x, y), \frac{\delta(x, T x)+\delta(y, T y)}{2}, \frac{\delta(x, T y)+\delta(T x, y)}{2}\right\} .
$$

A mapping $\mathrm{T}$ is called a generalized quasi-contractive (see $[10,11,17])$ with respect to $\delta$ if

$$
M_{\delta}(x, y)=\max \{\delta(x, y), \delta(x, T x), \delta(y, T y), \delta(x, T y), \delta(T x, y)\}
$$

Lemma 1 (Lemma 1 of $[15])$ Let $(X, \delta)$ be a metric space, and $\mathcal{R}$ a transitive binary relation over $\mathrm{X}$. Assume that for $\mathrm{T}: \mathrm{X} \rightarrow \mathrm{X}$, the following conditions are satisfied:

(b1) there exists $\mathrm{x}_{0} \in \mathrm{X}$ such that $\mathrm{x}_{0} \mathcal{R} T \mathrm{x}_{0}$,

(b2) $\mathrm{T}$ is $\mathcal{R}$-preserving mapping,

(b3) $\mathrm{T}$ is generalized quasi-contractive with respect to $\delta$.

Then,

$$
\delta\left(x_{i}, x_{j}\right) \leq \varphi\left(\operatorname{diam}\left(O_{n}\left(x_{0}\right)\right)\right)
$$

for all $i ; j \in\{1, \ldots, n\}$.

In 2014 the concept of C-class functions were introduced by A.H.Ansari [2]. By using this concept we can generalize many fixed point theorems in the literature. C-class functions have been studied by many authors.and some fixed point results with applications (see eg., [3, 12, 18, 4, 13]).

Definition 5 [2] A mapping $\mathrm{F}:[0, \infty)^{2} \rightarrow \mathbb{R}$ is called $\mathrm{C}$-class function if it is continuous and satisfies following axioms:

(1) $F(s, t) \leq s$,

(2) $\mathrm{F}(\mathrm{s}, \mathrm{t})=\mathrm{s}$ implies that either $\mathrm{s}=0$ or $\mathrm{t}=0$; for all $\mathrm{s}, \mathrm{t} \in[0, \infty)$.

Note for some $F$ we have that $F(0,0)=0$.

We denote $\mathrm{C}$-class functions as $\mathcal{C}$. 
Example 1 [2] The following functions $\mathrm{F}:[0, \infty)^{2} \rightarrow \mathbb{R}$ are elements of $\mathcal{C}$, for all $\mathrm{s}, \mathrm{t} \in[0, \infty)$ :

(1) $F(s, t)=s-t, F(s, t)=s \Rightarrow t=0$;

(2) $F(s, t)=m s, 0<m<1, F(s, t)=s \Rightarrow s=0$;

(3) $F(s, t)=\frac{s}{(1+t)^{r}}, r \in(0, \infty), F(s, t)=s \Rightarrow s=0$ or $t=0$;

(4) $F(s, t)=\log \left(t+a^{s}\right) /(1+t), a>1, F(s, t)=s \Rightarrow s=0$ or $t=0$;

(5) $\mathrm{F}(\mathrm{s}, \mathrm{t})=\ln \left(1+\mathrm{a}^{\mathrm{s}}\right) / 2, \mathrm{a}>\mathrm{e}, \mathrm{F}(\mathrm{s}, 1)=\mathrm{s} \Rightarrow \mathrm{s}=0$;

(6) $F(s, t)=(s+l)^{\left(1 /(1+t)^{r}\right)}-l, l>1, r \in(0, \infty), F(s, t)=s \Rightarrow t=0$;

(7) $F(s, t)=s \log _{t+a} a, a>1, F(s, t)=s \Rightarrow s=0$ or $t=0$;

(8) $F(s, t)=s-\left(\frac{1+s}{2+s}\right)\left(\frac{t}{1+t}\right), F(s, t)=s \Rightarrow t=0$;

(9) $\mathrm{F}(\mathrm{s}, \mathrm{t})=s \beta(\mathrm{s}), \beta:[0, \infty) \rightarrow[0,1)$, and is continuous, $\mathrm{F}(\mathrm{s}, \mathrm{t})=\mathrm{s} \Rightarrow$ $s=0$;

(10) $F(s, t)=s-\frac{t}{k+t}, F(s, t)=s \Rightarrow t=0$;

(11) $\mathrm{F}(\mathrm{s}, \mathrm{t})=\mathrm{s}-\varphi(\mathrm{s}), \mathrm{F}(\mathrm{s}, \mathrm{t})=\mathrm{s} \Rightarrow \mathrm{s}=0$, here $\varphi:[0, \infty) \rightarrow[0, \infty)$ is a continuous function such that $\varphi(\mathrm{t})=0 \Leftrightarrow \mathrm{t}=0$;

(12) $\mathrm{F}(\mathrm{s}, \mathrm{t})=\operatorname{sh}(\mathrm{s}, \mathrm{t}), \mathrm{F}(\mathrm{s}, \mathrm{t})=\mathrm{s} \Rightarrow \mathrm{s}=0$, here $\mathrm{h}:[0, \infty) \times[0, \infty) \rightarrow[0, \infty)$ is a continuous function such that $\mathrm{h}(\mathrm{t}, \mathrm{s})<1$ for all $\mathrm{t}, \mathrm{s}>0$;

(13) $F(s, t)=s-\left(\frac{2+t}{1+t}\right) t, F(s, t)=s \Rightarrow t=0$;

(14) $F(s, t)=\sqrt[\mathfrak{n}]{\ln \left(1+s^{\mathfrak{n}}\right)}, F(s, t)=s \Rightarrow s=0$;

(15) $\mathrm{F}(\mathrm{s}, \mathrm{t})=\phi(\mathrm{s}), \mathrm{F}(\mathrm{s}, \mathrm{t})=\mathrm{s} \Rightarrow \mathrm{s}=0$, here $\phi:[0, \infty) \rightarrow[0, \infty)$ is a upper semicontinuous function such that $\phi(0)=0$, and $\phi(\mathrm{t})<\mathrm{t}$ for $\mathrm{t}>0$;

(16) $\mathrm{F}(\mathrm{s}, \mathrm{t})=\frac{\mathrm{s}}{(1+\mathrm{s})^{\mathrm{r}}}, \mathrm{r} \in(0, \infty), \mathrm{F}(\mathrm{s}, \mathrm{t})=\mathrm{s} \Rightarrow \mathrm{s}=0$;

(17) $\mathrm{F}(\mathrm{s}, \mathrm{t})=\vartheta(\mathrm{s}), \vartheta: \mathbb{R}^{+} \times \mathbb{R}^{+} \rightarrow \mathbb{R}$ is a generalized Mizoguchi-Takahashi type function, $\mathrm{F}(\mathrm{s}, \mathrm{t})=\mathrm{s} \Rightarrow \mathrm{s}=0$;

(18) $\mathrm{F}(\mathrm{s}, \mathrm{t})=\frac{\mathrm{s}}{\Gamma(1 / 2)} \int_{0}^{\infty} \frac{\mathrm{e}^{-\mathrm{x}}}{\sqrt{\mathrm{x}}+\mathrm{t}} \mathrm{d} x$, where $\Gamma$ is the Euler Gamma function.

Denote by $\Psi$ the family of continuous and monotone nondecreasing functions $\psi:[0, \infty) \rightarrow[0, \infty)$ such that $\psi(t)=0$ if and only if $t=0$ and by $\Phi_{\mathfrak{u}}$ the family of continuous functions $\varphi:[0, \infty) \rightarrow[0, \infty)$ such that $\varphi(t)>0$ for all $\mathrm{t}>0$. 
Definition 6 Assume that for $\mathrm{T}: \mathrm{X} \rightarrow \mathrm{X}$ there exists $\varphi \in \Phi_{\mathfrak{u}}, \psi \in \Psi, \mathrm{F} \in \mathcal{C}$ such that

$\psi(\delta(T x, T y)) \leq F\left(\psi\left(M_{\delta}(x, y)\right), \varphi\left(M_{\delta}(x, y)\right)\right)$, for all $x, y \in X$ with $x \mathcal{S} y$.

A mapping $\mathrm{T}$ is called a generalized $\mathrm{F} \psi \varphi$-contractive with respect to $\delta$, if

$$
M_{\delta}(x, y)=\max \left\{\delta(x, y), \frac{\delta(x, T x)+\delta(y, T y)}{2}, \frac{\delta(x, T y)+\delta(T x, y)}{2}\right\} .
$$

A mapping $\mathrm{T}$ is called a generalized quasi- $\mathrm{F} \psi \varphi$-contractive with respect to $\delta$, if

$$
M_{\delta}(x, y)=\max \{\delta(x, y), \delta(x, T x), \delta(y, T y), \delta(x, T y), \delta(T x, y)\}
$$

Lemma 2 [9] Suppose $(\mathrm{X}, \delta)$ be a metric space. Let $\left\{\mathrm{x}_{\mathrm{n}}\right\}$ be a sequence in $\mathrm{X}$ such that $\delta\left(x_{n}, x_{n+1}\right) \rightarrow 0$ as $n \rightarrow \infty$. If $\left\{x_{n}\right\}$ is not a Cauchy sequence then there exist an $\varepsilon>0$ and sequences of positive integers $\{m(k)\}$ and $\{n(k)\}$ with $\mathrm{m}(\mathrm{k})>\mathrm{n}(\mathrm{k})>\mathrm{k}$ such that $\delta\left(\mathrm{x}_{\mathrm{m}(\mathrm{k})}, \mathrm{x}_{\mathrm{n}(\mathrm{k})}\right) \geq \varepsilon, \delta\left(\mathrm{x}_{\mathrm{m}(\mathrm{k})-1}, \mathrm{x}_{\mathrm{n}(\mathrm{k})}\right)<\varepsilon$ and

(i) $\lim _{k \rightarrow \infty} \delta\left(x_{m(k)-1}, x_{n(k)+1}\right)=\varepsilon$,

(ii) $\lim _{k \rightarrow \infty} \delta\left(x_{m(k)}, x_{n(k)}\right)=\varepsilon$,

(iii) $\lim _{k \rightarrow \infty} \delta\left(x_{m(k)-1}, x_{n(k)}\right)=\varepsilon$,

(iv) $\lim _{k \rightarrow \infty} \delta\left(x_{m(k)+1}, x_{n(k)+1}\right)=\varepsilon$,

(v) $\lim _{k \rightarrow \infty} \delta\left(x_{m(k)}, x_{n(k)-1}\right)=\varepsilon$.

Definition 7 We say $(\psi, \phi, F)$ is monotone if $x \leq y \Longrightarrow F(\psi(x), \phi(x)) \leq$ $\mathrm{F}(\psi(\mathrm{y}), \phi(y))$.

Example 2 Let $F(s, t)=s-t, \phi(x)=\sqrt{x}$

$$
\psi(x)= \begin{cases}\sqrt{x} & \text { if } 0 \leq x \leq 1 \\ x^{2}, & \text { if } x>1\end{cases}
$$

Then $(\psi, \phi, \mathrm{F})$ is monotone.

Example 3 Let $\mathrm{F}(\mathrm{s}, \mathrm{t})=\mathrm{s}-\mathrm{t}, \phi(\mathrm{x})=\mathrm{x}^{2}$

$$
\psi(x)= \begin{cases}\sqrt{x} & \text { if } 0 \leq x \leq 1 \\ x^{2}, & \text { if } x>1\end{cases}
$$

Then $(\psi, \phi, F)$ is not monotone. 
In this paper we prove some Maia type fixed point results via C-class function in the setting of two metrics space endowed with a binary relation. Our results generalized and extended many existing fixed point theorems for generalized contractive and quasi-contractive mappings in a metric space endowed with binary relation.

\section{Main results}

Our first main result is the following theorem.

Theorem 2 Let $(\mathrm{X}, \mathrm{d}, \delta)$ be a bimetric space and $\mathrm{T}: \mathrm{X} \rightarrow \mathrm{X}$. Assume that the following conditions are satisfied:

(A1) $\mathrm{d}(x, y) \leq \delta(x, y)$ for all $x, y \in X$

(A2) (X, d) is T-orbitally complete,

(A3) $\mathrm{T}$ is continuous with respect to $\mathrm{d}$,

(A4) $\mathrm{T}$ is $\mathcal{S}$-preserving,

(A5) there exists $\mathrm{x}_{0} \in \mathrm{X}$ with $\mathrm{x}_{0} \mathcal{S} T \mathrm{x}_{0}$,

(A6) $\mathrm{T}$ is a generalized $\mathrm{F} \psi \varphi$-contractive with respect to $\delta$.

Then $\mathrm{T}$ has a fixed point $\chi^{*}$ in $\mathrm{X}$. Moreover, if in addition $\mathrm{Fix}(\mathrm{T})$ is $\mathcal{S}$-directed then $\mathrm{x}^{*}$ is the unique fixed point of $\mathrm{T}$ in $\mathrm{X}$.

Proof. From (A5), there exists $x_{0} \in X$ with $x_{0} \mathcal{S} T x_{0}$ and from (A4) $T$ is $\mathcal{S}$ preserving, we get

$$
x_{n} \mathcal{S} \mathrm{x}_{\mathrm{n}} \quad \text { for all } \mathrm{n} \in \mathrm{N} .
$$

If $x_{n}=T x_{n}$ then $x_{n}$ is a fixed point of $T$. Suppose that $x_{n} \neq T x_{n}$ for all $n$. Since (2) is satisfied for all $n \geq 1$, by applying the contraction condition (A6), and note that $\psi$ is nondecreasing, we have

$$
\begin{aligned}
& \psi\left(\delta\left(x_{n}, x_{n+1}\right)=\psi\left(\delta\left(x_{n}, T x_{n}\right)\right) \leq F\left(\psi\left(M_{\delta}\left(x_{n-1}, x_{n}\right)\right), \varphi\left(M_{\delta}\left(x_{n-1}, x_{n}\right)\right)\right.\right. \\
& <\psi\left(M_{\delta}\left(x_{n-1}, x_{n}\right)\right) \\
& \leq \psi\left(\max \left\{\delta\left(x_{n-1}, x_{n}\right), \delta\left(x_{n}, x_{n+1}\right)\right\}\right) .
\end{aligned}
$$

Now, we will show that $\left\{x_{n}\right\}$ is a Cauchy sequence in $(X, \delta)$. If for some $n \geq 1$ we have $\delta\left(x_{n-1}, x_{n}\right) \leq \delta\left(x_{n}, x_{n+1}\right)$, then we get

$$
\psi\left(\delta\left(x_{n}, x_{n+1}\right)\right)=F\left(\psi\left(\delta\left(x_{n}, x_{n+1}\right)\right), \varphi\left(\delta\left(x_{n}, x_{n+1}\right)\right)\right) .
$$


Thus, $\psi\left(\delta\left(x_{n}, x_{n+1}\right)\right)=0$ or $\varphi\left(\delta\left(x_{n}, x_{n+1}\right)\right)=0$, and therefore $\delta\left(x_{n}, x_{n+1}\right)=0$ which is contradiction. We get $\delta\left(x_{n-1}, x_{n}\right)>\delta\left(x_{n}, x_{n+1}\right)$ and

$$
\psi\left(\delta\left(x_{n}, x_{n+1}\right)\right)=F\left(\psi\left(\delta\left(x_{n-1}, x_{n}\right)\right), \varphi\left(\delta\left(x_{n-1}, x_{n}\right)\right)\right) .
$$

Hence $\left\{\delta\left(x_{n}, x_{n+1}\right)\right\}$ is a non-increasing sequence of positive real numbers. Thus there exist $\mathrm{L} \geq 0$ such that

$$
\lim _{n \rightarrow \infty} \delta\left(x_{n}, x_{n+1}\right)=L \text {. }
$$

Taking the limit in equation (3) as $\mathfrak{n} \rightarrow \infty$ and using (4) and the properties of $F$ and $\varphi$, we have

$$
\psi(\mathrm{L}) \leq \mathrm{F}(\psi(\mathrm{L}), \varphi(\mathrm{L})) .
$$

Thus $\psi(\mathrm{L})=0$ or $\varphi(\mathrm{L})=0$, and so $\mathrm{L}=0$. Therefore

$$
\lim _{n \rightarrow \infty} \delta\left(x_{n}, x_{n+1}\right)=0 .
$$

Let us show that $\left\{x_{n}\right\}$ is a Cauchy sequence. Suppose to the contrary that $\left\{x_{n}\right\}$ is not a Cauchy sequence.

By Lemma 2 there exists $\varepsilon>0$ for which we can find subsequences $\left\{x_{\mathfrak{n}(k)}\right\}$ and $\left\{x_{m(k)}\right\}$ of $\left\{x_{n}\right\}$ with $n(k)>m(k)>k$ such that

$$
\delta\left(x_{\mathfrak{m}(\mathrm{k})}, x_{\mathfrak{n}(\mathrm{k})+1}\right), \delta\left(x_{\mathfrak{m}(\mathrm{k})}, x_{\mathfrak{n}(\mathrm{k})}\right), \delta\left(x_{\mathfrak{m}(\mathrm{k})-1}, x_{\mathfrak{n}(\mathrm{k})+1}\right), \delta\left(x_{\mathfrak{m}(\mathrm{k})-1}, x_{\mathfrak{n}(\mathrm{k})}\right) \rightarrow \varepsilon .
$$

Now from (1) we have

$$
\begin{aligned}
\psi\left(\delta\left(x_{\mathfrak{m}(k)}, x_{\mathfrak{n}(k)}\right)\right) & =\psi\left(\delta\left(T x_{\mathfrak{m}(k)-1}, T x_{\mathfrak{n}(k)-1}\right)\right) \\
& \leq F\left(\psi\left(M_{\delta}\left(x_{\mathfrak{m}(k)-1}, x_{\mathfrak{n}(k)-1}\right)\right), \varphi\left(M_{\delta}\left(x_{\mathfrak{m}(k)-1}, x_{\mathfrak{n}(k)-1}\right)\right)\right)
\end{aligned}
$$

where

$$
\begin{aligned}
M_{\delta}\left(x_{\mathfrak{m}(\mathrm{k})-1}, x_{\mathfrak{n}(\mathrm{k})-1}\right)= & \max \left\{\delta\left(x_{\mathfrak{m}(\mathrm{k})-1}, x_{\mathfrak{n}(\mathrm{k})-1}\right),\right. \\
& \frac{\delta\left(x_{\mathfrak{m}(\mathrm{k})-1}, T x_{\mathfrak{m}(\mathrm{k})-1}\right)+\delta\left(x_{\mathfrak{n}(\mathrm{k})-1}, T x_{\mathfrak{n}(\mathrm{k})-1}\right)}{2}, \\
& \left.\frac{\delta\left(x_{\mathfrak{m}(\mathrm{k})-1}, T x_{\mathfrak{n}(\mathrm{k})-1}\right)+\delta\left(\mathrm{T} x_{\mathfrak{m}(\mathrm{k})-1}, x_{\mathfrak{n}(\mathrm{k})-1}\right)}{2}\right\} .
\end{aligned}
$$

From above and (6), as $k \rightarrow \infty$ we have

$$
\psi(\varepsilon) \leq \mathrm{F}(\psi(\varepsilon), \varphi(\varepsilon)) .
$$


Thus $\psi(\varepsilon)=0$ or $\varphi(\varepsilon)=0$ and therefore $\varepsilon=0$ which is contradiction. Consequently the sequence $\left\{x_{n}\right\}$ is $\delta$-Cauchy, so by (A1), $\left\{x_{n}\right\}$ is d-Cauchy too. Since from (A2), we have that the metric space $(X, d)$ is T-orbitally complete, then there exists $\chi^{*} \in X$ such that

$$
\lim _{n \rightarrow \infty} \delta\left(x_{n}, x^{*}\right)=0
$$

From (A3), we have that $\mathrm{T}$ is continuous with respect to $d$, and, so it follows that $x^{*}=\lim _{n \rightarrow \infty} T x_{n}=T\left(\lim _{n \rightarrow \infty} x_{n}\right)=T x^{*}$, that is, $x^{*}$ is a fixed point of $T$.

Next suppose that $\operatorname{Fix}(T)$ is $\mathcal{S}$-directed, and we will show that $x^{*}$ is the unique fixed point of $T$ in $X$. Suppose that $y^{*} \in \operatorname{Fix}(T)$ is another fixed point of $\mathrm{T}$. Then, there exists $z_{0} \in X$ such that $z_{0} \mathcal{S} x^{*}$ and $z_{0} \mathcal{S} y^{*}$. Define the sequence $\left\{z_{n}\right\}$ in $X$ by $z_{n+1}=T z_{n}$ for all $n \geq 0$. Since $T$ is $\mathcal{S}$-preserving, for all $n \geq 0$ we have $z_{n} \mathcal{S} x^{*}$ and $z_{n} \mathcal{S} y^{*}$. Applying (A6), for all $n \geq 0$ and note $\delta\left(z_{n}, z_{n+1}\right) \leq$ $\delta\left(z_{n}, x^{*}\right)+\delta\left(z_{n+1}, x^{*}\right)$ we get

$$
\begin{aligned}
\psi & \left(\delta\left(z_{n+1}, x^{*}\right)\right)=\psi\left(\delta\left(T z_{n}, T x^{*}\right)\right)=F\left(\psi\left(M_{\delta}\left(z_{n}, x^{*}\right)\right), \varphi\left(M_{\delta}\left(z_{n}, x^{*}\right)\right)\right) \\
\leq & F\left(\psi\left(\max \left\{\delta\left(z_{n}, x^{*}\right), \frac{\delta\left(z_{n}, T z_{n}\right)+\delta\left(x^{*}, T x^{*}\right)}{2}, \frac{\delta\left(z_{n}, T x^{*}\right)+\delta\left(x^{*}, T z_{n}\right)}{2}\right\}\right),\right. \\
& \left.\varphi\left(\max \left\{\delta\left(z_{n}, x^{*}\right), \frac{\delta\left(z_{n}, T z_{n}\right)+\delta\left(x^{*}, T x^{*}\right)}{2}, \frac{\delta\left(z_{n}, T x^{*}\right)+\delta\left(x^{*}, T z_{n}\right)}{2}\right\}\right)\right) \\
= & F\left(\psi\left(\max \left\{\delta\left(z_{n}, x^{*}\right), \frac{\delta\left(z_{n}, z_{n+1}\right)+\delta\left(x^{*}, x^{*}\right)}{2}, \frac{\delta\left(z_{n}, x^{*}\right)+\delta\left(x^{*}, z_{n+1}\right)}{2}\right\}\right),\right. \\
& \left.\varphi\left(\max \left\{\delta\left(z_{n}, x^{*}\right), \frac{\delta\left(z_{n}, z_{n+1}\right)+\delta\left(x^{*}, x^{*}\right)}{2}, \frac{\delta\left(z_{n}, x^{*}\right)+\delta\left(x^{*}, z_{n+1}\right)}{2}\right\}\right)\right) \\
\leq & F\left(\psi\left(\max \left\{\delta\left(z_{n}, x^{*}\right), \delta\left(z_{n+1}, x^{*}\right)\right\}\right), \varphi\left(\max \left\{\delta\left(z_{n}, x^{*}\right), \delta\left(z_{n+1}, x^{*}\right)\right\}\right)\right) .
\end{aligned}
$$

Now we will show that $\lim _{n \rightarrow \infty} \delta\left(z_{n}, x^{*}\right)=0$. Without the loss of generality suppose that $\delta\left(z_{n}, x^{*}\right)>0$ for all $n$. Assume that for some $n$ we have $\delta\left(z_{n}, x^{*}\right) \leq$ $\delta\left(x^{*}, z_{\mathfrak{n}+1}\right)$. Hence we get

$$
\psi\left(\delta\left(z_{n+1}, \chi^{*}\right)\right)=F\left(\psi\left(\delta\left(z_{n+1}, x^{*}\right)\right), \varphi\left(\delta\left(z_{n+1}, x^{*}\right)\right)\right) .
$$

Hence $\psi\left(\delta\left(z_{n+1}, x^{*}\right)\right)=0$ or $\varphi\left(\delta\left(z_{n+1}, x^{*}\right)\right)=0$ and therefore $\delta\left(z_{n+1}, x^{*}\right)=0$, which is a contradiction. Then, for all $n \geq 0$ we have $\delta\left(z_{n}, x^{*}\right)>\delta\left(x^{*}, z_{n+1}\right)$. Consequently, for all $n$ we obtain

$$
\psi\left(\delta\left(z_{n+1}, x^{*}\right)\right)=F\left(\psi\left(\delta\left(z_{n}, x^{*}\right)\right), \varphi\left(\delta\left(z_{n}, x^{*}\right)\right)\right) \leq \psi\left(\delta\left(z_{n}, x^{*}\right)\right)
$$


that is, $\left\{\delta\left(z_{n}, x^{*}\right)\right\}$ is a non-increasing sequence of positive real numbers. Thus there exist $L \geq 0$ such that

$$
\lim _{n \rightarrow \infty} \delta\left(z_{n}, x^{*}\right)=L .
$$

Taking the limit in equation (8) as $n \rightarrow \infty$ and using (9) and the properties of $\mathrm{F}$ and $\varphi$ we have

$$
\psi(\mathrm{L}) \leq \mathrm{F}(\psi(\mathrm{L}), \varphi(\mathrm{L})) .
$$

Thus $\psi(\mathrm{L})=0$ or $\varphi(\mathrm{L})=0$ and therefore $\mathrm{L}=0$. Thus

$$
\lim _{n \rightarrow \infty} \delta\left(z_{n}, x^{*}\right)=0
$$

Similarly we can prove that $\lim _{n \rightarrow \infty} \delta\left(z_{n}, y^{*}\right)=0$. Hence $x^{*}=y^{*}$.

To prove our next main result we need the following lemmas which will be used in the sequel.

Lemma 3 Let $\mathrm{n} \in \mathbb{N},(X, \delta)$ be a metric space, and $\mathcal{R}$ a transitive binary relation over $\mathrm{X}$ Assume that for $\mathrm{T}: \mathrm{X} \rightarrow \mathrm{X}$ the following conditions are satisfied:

(a1) there exists $x_{0} \in X$ such that $x_{0} \mathcal{R} \mathrm{Tx}_{0}$,

(a2) $\mathrm{T}$ is $\mathcal{R}$-preserving mapping,

(a3) $\mathrm{T}$ is generalized quasi- $\mathrm{F} \varphi$-contractive with respect to $\delta$ and $(\psi, \varphi, \mathrm{F})$ is monotone.

Then

$$
\psi\left(\delta\left(x_{i}, x_{j}\right)\right) \leq F\left(\psi\left(\operatorname{diam}\left(O_{n}\left(x_{0}\right)\right)\right), \varphi\left(\operatorname{diam}\left(O_{n}\left(x_{0}\right)\right)\right)\right),
$$

for all $i, j \in\{1, \ldots, n\}$.

Proof. From (a1) there exists $x_{0} \in X$ such that $x_{0} \mathcal{R} x_{1}$. Hence by (a2) we get $x_{k} \mathcal{R} x_{k+1}$ for all k. Since $\mathcal{R}$ is transitive, then

$$
x_{i-1} \mathcal{R} x_{j-1} \quad \text { for all } 1 \leq i<j \leq n .
$$

We note that $x_{i-1}, x_{i}, x_{j-1}, x_{j} \in O_{n}\left(x_{0}\right)$. Now using (a3) and (11) we get

$$
\begin{aligned}
\psi\left(\delta\left(T x_{i-1}, T x_{j-1}\right)\right) & \leq F\left(\psi\left(M_{\delta}\left(x_{i-1}, x_{j-1}\right)\right), \varphi\left(M_{\delta}\left(x_{i-1}, x_{j-1}\right)\right)\right) \\
& =F\left(\psi \left(\operatorname { m a x } \left\{\delta\left(x_{i-1}, x_{j-1}\right), \delta\left(x_{i-1}, T x_{i-1}\right),\right.\right.\right.
\end{aligned}
$$




$$
\begin{aligned}
& \left.\left.\delta\left(x_{j-1}, T x_{j-1}\right), \delta\left(x_{i-1}, T x_{j-1}\right), \delta\left(T x_{i-1}, x_{j-1}\right)\right\}\right), \\
& \varphi\left(\operatorname { m a x } \left\{\delta\left(x_{i-1}, x_{j-1}\right), \delta\left(x_{i-1}, T x_{i-1}\right),\right.\right. \\
& \left.\left.\left.\delta\left(x_{j-1}, T x_{j-1}\right), \delta\left(x_{i-1}, T x_{j-1}\right), \delta\left(T x_{i-1}, x_{j-1}\right)\right\}\right)\right),
\end{aligned}
$$

which implies (10).

Now we are ready to state our second main result.

Theorem 3 Let $(\mathrm{X}, \mathrm{d}, \delta)$ be a bimetric space, $\mathcal{R}$ a transitive binary relation over $\mathrm{X}$ and $\mathrm{T}: \mathrm{X} \rightarrow \mathrm{X}$. Assume that the following conditions are satisfied:

(B1) $\mathrm{d}(\mathrm{x}, \mathrm{y}) \leq \delta(x, y)$ for all $x, y \in X$,

(B2) (X, d) is T-orbitally complete,

(B3) $\mathrm{T}$ is continuous with respect to $\mathrm{d}$,

(B4) $\mathrm{T}$ is $\mathcal{R}$-preserving,

(B5) there exists $\mathrm{x}_{0} \in \mathrm{X}$ with $\mathrm{x}_{0} \mathcal{R} \mathrm{Tx}_{0}$,

(B6) $\mathrm{T}$ is a generalized quasi-F $\psi \varphi$-contractive with respect to $\delta$ and $(\psi, \varphi, \mathrm{F})$ is monotone.

Then $\mathrm{T}$ has a fixed point $\chi^{*}$ in $\mathrm{X}$. Moreover if in addition $\mathcal{R}$ is symmetric and Fix $(\mathrm{T})$ is $\mathcal{R}$-directed then $\mathrm{x}^{*}$ is the unique fixed point of $\mathrm{T}$ in $\mathrm{X}$.

Proof. Let $x_{0} \in X$ and $x_{0} R T x_{0}$. Define a sequence $\left\{x_{n}\right\}$ in $X$ by $x_{n+1}=T x_{n}$, for all $n \geq 0$. Since $T$ is an $\mathcal{R}$-preserving, then $x_{n} \mathcal{R} x_{n+1}$ for all $n$. Let $n$ and $m$, $n<m$ be any positive integers. From (B6) and Lemma 3 it follows

$$
\begin{aligned}
& \psi\left(\delta\left(T^{n} x_{0}, T^{m} x_{0}\right)\right)=\psi\left(\delta\left(T^{n-1} x_{0}, T^{m-n+1} T^{n-1} x_{0}\right)\right) \\
& F\left(\psi\left(\operatorname{diam}\left(O_{m-n+1}\left(T^{n-1} x_{0}\right)\right)\right), \varphi\left(\operatorname{diam}\left(O_{m-n+1}\left(T^{n-1} x_{0}\right)\right)\right)\right) .
\end{aligned}
$$

From Remark 1 there exists an integer $k_{1}, 1 \leq k_{1} \leq m-n+1$ such that

$$
\left.\operatorname{diam}\left(\mathrm{O}_{m-n+1}\left(T^{n-1} x_{0}\right)\right)\right)=\delta\left(T^{n-1} x_{0}, T^{k} T^{n-1} x_{0}\right) .
$$

Using Lemma 3 again we get combining the above inequalities

$$
\begin{aligned}
\psi\left(\delta\left(T^{n} x_{0}, T^{m} x_{0}\right)\right)= & \psi\left(\delta\left(T^{n-1} x_{0}, T^{m-n+1} T^{n-1} x_{0}\right)\right) \\
& F\left(\psi\left(\operatorname{diam}\left(O_{m-n+1}\left(T^{n-1} x_{0}\right)\right)\right), \varphi\left(\operatorname{diam}\left(O_{m-n+1}\left(T^{n-1} x_{0}\right)\right)\right)\right) \\
& \psi\left(\operatorname{diam}\left(O_{m-n+1}\left(T^{n-1} x_{0}\right)\right)\right)=\psi\left(\delta\left(T^{n-1} x_{0}, T^{k} T^{n-1} x_{0}\right)\right)
\end{aligned}
$$




$$
\begin{aligned}
& \leq F\left(\psi\left(\operatorname{diam}\left(\mathrm{O}_{\mathrm{k}_{1}+1}\left(\mathrm{~T}^{\mathrm{n}-2} \chi_{0}\right)\right)\right), \varphi\left(\operatorname{diam}\left(\mathrm{O}_{\mathrm{k}_{1}+1}\left(\mathrm{~T}^{\mathrm{n}-2} \mathbf{x}_{0}\right)\right)\right)\right) \\
& \leq F\left(\psi\left(\operatorname{diam}\left(\mathrm{O}_{m-n+2}\left(T^{n-2} \chi_{0}\right)\right)\right), \varphi\left(\operatorname{diam}\left(\mathrm{O}_{m-n+2}\left(T^{n-2} \chi_{0}\right)\right)\right)\right) .
\end{aligned}
$$

Continue this process we obtain

$$
\begin{aligned}
\psi\left(\delta\left(T^{n} x_{0}, T^{m} x_{0}\right)\right)= & \psi\left(\delta\left(T^{n-1} x_{0}, T^{m-n+1} T^{n-1} x_{0}\right)\right) \\
& F\left(\psi\left(\operatorname{diam}\left(O_{m-n+1}\left(T^{n-1} x_{0}\right)\right)\right), \varphi\left(\operatorname{diam}\left(O_{m-n+1}\left(T^{n-1} x_{0}\right)\right)\right)\right) \\
& \psi\left(\operatorname{diam}\left(O_{m-n+1}\left(T^{n-1} x_{0}\right)\right)\right)=\psi\left(\delta\left(T^{n-1} x_{0}, T^{k} T^{n-1} x_{0}\right)\right) \\
\leq & F\left(\psi\left(\operatorname{diam}\left(O_{k_{1}+1}\left(T^{n-2} x_{0}\right)\right)\right), \varphi\left(\operatorname{diam}\left(O_{k_{1}+1}\left(T^{n-2} x_{0}\right)\right)\right)\right) \\
\leq & F\left(\psi\left(\operatorname{diam}\left(O_{m-n+2}\left(T^{n-2} x_{0}\right)\right)\right), \varphi\left(\operatorname{diam}\left(O_{m-n+2}\left(T^{n-2} x_{0}\right)\right)\right)\right) \\
\vdots & \\
\leq & F\left(\psi\left(\operatorname{diam}\left(O_{m}\left(x_{0}\right)\right)\right), \varphi\left(\operatorname{diam}\left(O_{m}\left(x_{0}\right)\right)\right)\right) \\
\leq & F\left(\psi\left(\delta\left(T^{n-1} x_{0}, T^{m-1} x_{0}\right)\right), \varphi\left(\delta\left(T^{n-1} x_{0}, T^{m-1} x_{0}\right)\right)\right) .
\end{aligned}
$$

Hence

$$
\psi(\varepsilon) \leq \mathrm{F}(\psi(\varepsilon), \varphi(\varepsilon)) .
$$

Thus $\psi(\varepsilon)=0$ or $\varphi(\varepsilon)=0$, that is $\varepsilon=0$. It follows that the sequence $\left\{T^{n} \chi_{0}\right\}$ is a $\delta$-Cauchy sequence. Therefore by (B1) the sequence $\left\{T^{n} x_{0}\right\}$ is a d-Cauchy sequence too. Since the metric space $(X, d)$ is T-orbitally complete we deduce that the sequence $\left\{T^{n} x_{0}\right\}$ converges to some $x^{*}$ in $X$. From (B3) $T$ is continuous with respect to $d$, so $x^{*}=\lim _{n \rightarrow \infty} T x_{n}=T\left(\lim _{n \rightarrow \infty} x_{n}\right)=T x^{*}$ and $x^{*}$ is a fixed point of $\mathrm{T}$.

Now suppose that $\operatorname{Fix}(T)$ is $\mathcal{R}$-directed. We claim that the fixed point is unique. Let $x^{*}$ and $y^{*}$ be two fixed points of T. Suppose that $x^{*} \neq y^{*}$. Since $\operatorname{Fix}(T)$ is $\mathcal{R}$-directed, then there exists $z \in X$ such that $z \mathcal{R} x^{*}$ and $z \mathcal{R} y^{*}$. By the transitivity of $\mathcal{R}$ we have $x^{*} \mathcal{R} y^{*}$. Then we apply the contraction condition (B6) and get

$$
\begin{aligned}
\psi\left(\delta\left(x^{*}, y^{*}\right)\right)= & \psi\left(\delta\left(T x^{*}, T y^{*}\right)\right) \\
\leq & F\left(\psi\left(\max \left\{\delta\left(x^{*}, y^{*}\right), \delta\left(x^{*}, T x^{*}\right), \delta\left(y^{*}, T y^{*}\right), \delta\left(x^{*}, T y^{*}\right), \delta\left(T x^{*}, y^{*}\right)\right\}\right),\right. \\
& \left.\varphi\left(\max \left\{\delta\left(x^{*}, y^{*}\right), \delta\left(x^{*}, T x^{*}\right), \delta\left(y^{*}, T y^{*}\right), \delta\left(x^{*}, T y^{*}\right), \delta\left(T x^{*}, y^{*}\right)\right\}\right)\right) .
\end{aligned}
$$

Hence

$$
\psi\left(\delta\left(x^{*}, y^{*}\right)\right) \leq F\left(\psi\left(\delta\left(x^{*}, y^{*}\right)\right), \varphi\left(\delta\left(x^{*}, y^{*}\right)\right)\right)
$$

and $\psi\left(\delta\left(x^{*}, y^{*}\right)\right)=0$ or $\varphi\left(\delta\left(x^{*}, y^{*}\right)\right)=0$. Therefore $\delta\left(x^{*}, y^{*}\right)=0$ and $x^{*}=y^{*}$. 
The following results are an immediate consequences of Theorems 2 and 3 .

Corollary 1 Theorem 1 is a particular case of Theorem 2.

Corollary 2 Let $(X, \preceq)$ be a partially ordered set and $(X, d, \delta)$ be a bimetric space and $\mathrm{T}: \mathrm{X} \rightarrow \mathrm{X}$. Assume that the following conditions are satisfied:

(C1) $\mathrm{d}(\mathrm{x}, \mathrm{y}) \leq \delta(\mathrm{x}, \mathrm{y})$, for all $\mathrm{x}, \mathrm{y} \in \mathrm{X}$,

(C2) $\mathrm{X}$ is complete with respect to $\mathrm{d}$,

(C3) $\mathrm{T}$ is continuous with respect to $\mathrm{d}$,

(C4) $\mathrm{T}$ is monotone nondecreasing mapping,

(C5) there exists $\mathrm{x}_{0} \in \mathrm{X}$ with $\mathrm{x}_{0} \preceq \mathrm{T} \mathrm{x}_{0}$,

(C6) there exists $\varphi \in \Phi$ such that

$$
\left.\psi(\delta(T x, T y)) \leq \psi\left(M_{\delta}(x, y)\right)-\varphi\left(M_{\delta}(x, y)\right)\right), \text { for all } x, y \text { in } X .
$$

Then $\mathrm{T}$ has a unique fixed point in $\mathrm{X}$.

Corollary 3 Let $(\mathrm{X}, \preceq)$ be a partially ordered set and $(\mathrm{X}, \mathrm{d})$ be a complete metric space. Assume that for $\mathrm{T}: \mathrm{X} \rightarrow \mathrm{X}$, the following conditions are satisfied:

(D1) $\mathrm{T}$ is continuous;

(D2) $\mathrm{T}$ is monotone nondecreasing mapping;

(D3) there exists $\mathrm{x}_{0} \in \mathrm{X}$ with $\mathrm{x}_{0} \preceq \mathrm{T} \mathrm{x}_{0}$;

(D4) there exists a constant $\alpha \in[0,1)$ such that

$$
\psi(\delta(T x, T y)) \leq \alpha \psi\left(M_{\delta}(x, y)\right), \quad \text { for all } x, y \text { in } X .
$$

Then $\mathrm{T}$ has a unique fixed point in $\mathrm{X}$.

Corollary 4 Let $(\mathrm{X}, \mathrm{d})$ be a complete metric space and $\mathrm{T}: \mathrm{X} \rightarrow \mathrm{X}$ be continuous mapping. Suppose there exists $\varphi \in \Phi$ such that

$$
\psi(\delta(T x, T y)) \leq \frac{\psi\left(M_{\delta}(x, y)\right)}{1+\varphi\left(M_{\delta}(x, y)\right)}, \quad \text { for all } x, y \text { in } X .
$$

Then $\mathrm{T}$ has a unique fixed point in $\mathrm{X}$. 


\section{Remark 3}

(1) If in Theorem 2 we put $\mathrm{F}(\mathrm{s}, \mathrm{t})=\mathrm{mt}, 0 \leq \mathrm{m}<1, \psi(\mathrm{t})=\phi(\mathrm{t})=\mathrm{t}$, then we obtain Maia's Theorem 1.

(2) If we use the same notations as in (1), and if we define relation $\mathcal{S}$ by $x \mathcal{S} y$ if and only if $\alpha \mathrm{d}(x \mathrm{Tx}) \leq \mathrm{d}(x, y)$ implies $d(T x, T y) \leq \beta d(x, y)$, where $\alpha \in(0,1 / 2), \beta \in(0,1)$, then when $T$ is continuous Theorem 2 implies Theorem 2.2 in $[29]$.

(3) Our results, when we put $F(s, t)=m t, 0 \leq m<1$, imply results from [15].

(4) Using Theorem of Singh [28] we note that our results are true under much less restricted condition, that is we do not need the continuity of $T$ with respect to $\mathrm{d}$ on $\mathrm{X}$, but only the continuity at a point.

\section{Application to Cauchy problem}

In this section, we study the Cauchy problem for a class of nonlinear differential equations, using the results obtained in the previous section. We just state the application part and we point out that the proof is on the lines of M.S. Khan at all [15]. So we omit it.

Example 4 Consider the nonlinear differential equation

$$
\psi(x)=\left\{\begin{array}{l}
x^{\prime}(t)=f(t, x(t)) \quad t \in[a, b] \\
x\left(t_{0}\right)=x_{0}
\end{array}\right.
$$

where $\mathrm{a}, \mathrm{b}, \mathrm{t}_{0} \in \mathbb{R}$ and $\mathrm{f}:[\mathrm{a}, \mathrm{b}] \times \mathbb{R} \rightarrow \mathbb{R}$. Let $\mathrm{X}=\mathrm{C}([\mathrm{a}, \mathrm{b}], \mathbb{R})$ denotes the space of all continuous $\mathbb{R}$-valued functions on $[\mathrm{a}, \mathrm{b}]$ with the metric $\mathrm{d}$ given by

$$
\mathrm{d}(\mathrm{u}, v)=\sup _{t \in[a, b]}|f(u(t), v(t))| \text {, for all } u, v \in X
$$

It is well known that $(\mathrm{X}, \mathrm{d})$ is a complete metric space. We define an order relation $\preceq$ on $\mathrm{X}$ by

$$
\mathrm{u} \preceq v \Leftrightarrow u(t) \leq v(t), \text { for all } \mathrm{t} \in[\mathrm{a}, \mathrm{b}]
$$

Consider the mapping $\mathrm{T}: \mathrm{C}([\mathrm{a}, \mathrm{b}], \mathbb{R}) \rightarrow \mathrm{C}([\mathrm{a}, \mathrm{b}], \mathbb{R})$ defined by

$$
\mathrm{T} x(\mathrm{t})=x_{0}+\int_{\mathrm{t}_{0}}^{\mathrm{t}} \mathrm{f}(\mathrm{s}, \mathrm{x}(\mathrm{s})) \mathrm{ds} ; \quad t \in[\mathrm{a}, \mathrm{b}]
$$


for all $\mathrm{x} \in \mathrm{C}([\mathrm{a}, \mathrm{b}], \mathbb{R})$. Clearly, $\chi^{*} \in \mathrm{C}([\mathrm{a}, \mathrm{b}], \mathbb{R})$ is a solution of $(12)$ if and only if $\mathrm{x}^{*}$ is a fixed point of $\mathrm{T}$.

Furthermore, we consider the following assumptions:

(H1) $f:[a, b] \times \mathbb{R} \rightarrow \mathbb{R}$ is continuous;

$(\mathrm{H} 2) \mathrm{f}:[\mathrm{a}, \mathrm{b}] \times \mathbb{R} \rightarrow \mathbb{R}$ is nondecreasing with respect to the second variable;

(H3) $|\mathrm{f}(\mathrm{t}, \mathrm{x}(\mathrm{t}))-\mathrm{f}(\mathrm{t}, \mathrm{y}(\mathrm{t}))| \leq \mathrm{L}|\mathrm{x}(\mathrm{t})-\mathrm{y}(\mathrm{t})|$ for all $\mathrm{x}(\mathrm{t}) \leq \mathrm{y}(\mathrm{t})$ and $\mathrm{t} \in[\mathrm{a}, \mathrm{b}]$.

It is worth noting that condition ( $\mathrm{H} 3)$ is weaker compared to those used by Maia for studying Cauchy problem in [16], that is, $\mathrm{f}$ is L-Lipschitzien function on the whole space.

By the proof of Theorem 6 in [15] we have

$$
\delta(x, y) \leq \exp (L(b-a)) d(x, y)
$$

and for $\lambda=\sqrt{1-\exp (L(a-b))}$, then we have

$$
d\left(T^{n} x, T^{n} y\right) \leq \exp (L(b-a)) d(x, y) \quad \text { for all } x \preceq y \text {. }
$$

We deduce by using Corollary 3 (see also [15]) that T has a unique fixed point $x^{*} \in C([a, b], \mathbb{R})$.

\section{Acknowledgements}

The authors are grateful to the anonymous reviewers for their careful reviews and very useful comments.

\section{References}

[1] R. P. Agarwal, E. Karapinar, D. O'Regan, Antonio Francisco RoldanLopez-de-Hierro, Fixed Point Theory in Metric Type Spaces, Springer International Publishing, Switzerland 2015.

[2] A. H. Ansari,Note on $\varphi-\psi$ - contractive type mappings and related fixed point, The $2^{\text {nd }}$ Regional Conference on Mathematics and Applications, Payame Noor University, 2014, pages 377-380. 
[3] A. H. Ansari, M. Demma, L. Guran and J. R. Lee, Fixed point results for C-class functions in modular metric spaces, J. Fixed Point Theory Appl., (2018) 20: 103.

[4] A. H. Ansari, V. Gupta, N.Mani, C-class functions on Some Coupled Fixed Point Theorems in partially ordered S-metric spaces, Communications Faculty of Sciences University of Ankara Series A1: Mathematics and Statistics, 68 (2) (2019), 1694-1708,.

[5] M. -E. Balazs, Maia type fixed point theorems for Ćirić-Prešić operators, Acta Univ. Sapientiae, Mathematica, 10, 1 (2018), 18-31.

[6] V. Berinde, A fixed point theorem of Maia type in K-metric spaces, Seminar on Fixed Point Theory (Cluj-Napoca), 3 (1991), 7-14.

[7] V. Berinde, Iterative Approximation of Fixed Points, Springer, Berlin, 2007.

[8] M. Berzig, Coincidence and common fixed point results on metric spaces endowed with an arbitrary binary relation and applications, J. Fixed Point Theory Appl., 12.1-2, (2012), 221-238.

[9] P. Chuadchawna, A. Kaewcharoen, S.Plubtieng, Fixed point theorems for generalized $\alpha-\eta-\psi$-Geraghty contraction type mappings in $\alpha-\eta$ complete metric spaces, J. Nonlinear Sci. Appl., 9 (2016), 471-485.

[10] Lj. B. Ćirić, A generalization of Banach's contraction principle, Proc. Amer. Math. Soc., 45.2 (1974), 267-273.

[11] Lj. B. Ćirić, Some recent results in metrical fixed point theory, University of Belgrade, Beograd 2003.

[12] D. Dhamodharan, Yumnam Rohen and Arslan Hojat Ansari, Fixed point theorems of C-class functions in $\mathrm{S}_{\mathrm{b}}$-metric space, Res. Fixed Point Theory Appl. Volume 2018, Article ID 2018018, 20 pages.

[13] V. Gupta, N. Mani, N. Sharma, Fixed point theorems for weak (,)- mappings satisfying generalized C-condition and its application to boundary value problem, Computational and Mathematical Methods, 1 (4), e1041, $1-12,2019$.

[14] W. Kirk, N. Shahzad, Fixed Point Theory in Distance Spaces, Springer International Publishing, Switzerland 2014. 
[15] M.S. Khan, M. Berzig and S. Chandok, Fixed point theorems in bimetric space endowed with binary relation and applications, Miskolc Mathematical Notes, Vol. 16 (2) (2015), 939-951.

[16] M. G. Maia, Un'osservazione sulle contrazioni metriche, Rend. Semin. Mat. Univ. Padova, 40 (1968), 139-143.

[17] E. Malkowsky and V. Rakočević, Advanced Functional Analysis, CRC Press, Taylor \& Francis Group, Boca Raton, FL, 2019.

[18] B. Moeini, C-class functions and some fixed point results with applications, LAMBERT Academic Publishing, 2018.

[19] A. S. Muresan, From Maia fixed point theorem to the fixed point theory in a set with two metrics, Carpatian J. Math., 23 (2007), 133-140.

[20] A. Petrusel and I. A. Rus, Fixed point theory in terms of a metric and of an order relation, Fixed Point Theory, 20 (2) (2019), 601-622.

[21] A. C. M. Ran and M. C. Reurings, A fixed point theorem in partially ordered sets and some applications to matrix equations, Proc. Amer. Math. Soc., 132 (2004), 1435-1443.

[22] D. O'Regan and A. Petrusel, Fixed point theorems for generalized contractions in ordered metric spaces, J. Math. Anal. Appl., 341(2008), 12411252.

[23] I. A. Rus, Basic problem for Maia's theorem, Sem. on Fixed Point Theory, Preprint, 3 (1981), Babes-Bolyai Univ., Cluj-Napoca, 112-115.

[24] I. A. Rus, Generalized Contractions and Applications, Cluj University Press, Cluj-Napoca, 2001.

[25] I. A. Rus, Data dependence of the fixed points in a set with two metrics, Fixed Point Theory, Volume 8 No. 1 (2007), 115-123.

[26] I. A. Rus, A. Petrusel, G. Petrusel, Fixed Point Theory, Cluj University Press Cluj-Napoca, 2008.

[27] B. Samet and M. Turinici, Fixed point theorems on a metric space endowed with an arbitrary binary relation and applications, Commun. Math. Anal., 13.2 (2012), 82-97. 
[28] S. P.Singh, On a fixed point theorem in metric space, Rend. Semin. Mat. Univ. Padova, 43 (1970), 229-232.

[29] T. Suzuki, A new type of fixed point theorem in metric spaces, Nonlinear Analysis, 71 (2009), 5313-5317.

[30] M. Turinici, Ran-Reurings theorems in ordered Metric Spaces, preprint, arxiv:1103.5207(2011).

[31] M. Turinici, Contractive maps in locally transitive relational metric spaces, The Scientific World Journal, vol. 2014, article ID 169358.

Received: February 2, 2020 